Check for updates

Cite this: Chem. Commun., 2021, 57,11859

Received 15th August 2021, Accepted 7th October 2021

DOI: $10.1039 / \mathrm{d} 1 \mathrm{cc} 04501 f$

rsc.li/chemcomm

\section{A high dimensional oxysulfide built from large iron-based clusters with partial charge-ordering $\dagger$}

\author{
Batoul Almoussawi, (D) Angel M. Arevalo-Lopez, (D) Pardis Simon (D) and \\ Houria Kabbour (D)*
}

\begin{abstract}
Herein we report the original $\mathrm{Ba}_{10} \mathrm{Fe}_{7.75} \mathrm{Zn}_{5.25} \mathrm{~S}_{18} \mathrm{Si}_{3} \mathrm{O}_{12}$ oxysulfide which crystallizes in a new structural type. Contrary to the usual oxychalcogenides, it crystallizes with a non-centrosymmetric 3D spatial network structure built from large magnetic clusters consisting of twelve $\left(\mathrm{Fe}^{2+/ 3+} / \mathrm{Zn}\right) \mathrm{S}_{3} \mathrm{O}$ tetrahedra decorating a central $\mathrm{Fe}^{2+} \mathrm{S}_{6}$ octahedron and exhibiting a spin glass state.
\end{abstract}

Mixed anion compounds frequently contain transition metals in unusual chemical environments and states due to heteroleptic coordination. These may lead to fascinating properties ${ }^{1}$ with new perspectives opened in several fields such as superconductors. ${ }^{2,3}$ Among them, Fe-based pnictide or chalcogenide layers have attracted much attention. Synthetic strategies based on mixed anion chemistry have given access to original phases ${ }^{4}$ and attractive physical properties. ${ }^{5}$ It has also led to enhanced performances in various fields of application such as photocatalysis or ionic conductivity. ${ }^{6}$ In this context, oxychalcogenides are increasingly investigated for diverse applications such as non-linear optics ${ }^{7}$ or thermoelectrics ${ }^{8}$ and are also emerging as visible light water-splitting photocatalysts. ${ }^{9-11}$ It is well established that oxychalcogenides tend to form layered structures, which is detailed in several reviews. ${ }^{8,12,13}$ This is favored by the very different ionic radii and electronegativities of $\mathrm{O}^{2-}(\chi=3.44)$ and $\mathrm{S}^{2-}(\chi=2.58)$ which arrange in distinct layers. Specific cation-anion affinities also influence the structural arrangement. A soft cation (more polarisable) and a hard cation (less polarisable) would prefer

Univ. Lille, CNRS, Centrale Lille, ENSCL, Univ. Artois, UMR 8181 - UCCS - Unité de Catalyse et Chimie du Solide, Lille F-59000, France.

E-mail: houria.kabbour@univ-lille.fr

$\dagger$ Electronic supplementary information (ESI) available: Experimental procedures and synthesis; Table S1 with structure solution and refinement details; Tables S2 and S3 with atomic positions and anisotropic thermal parameters; Table S4 with main distances, Table S5 with magnetic exchange path details (Fig. S4) and discussion; Vogel-Fulcher parameters (Table S6); $\mathrm{Ba}^{2+}$ environments (Fig. S1); Rietveld refinement (Fig. S2) and its discussion; magnetization at 2 and $300 \mathrm{~K}$ (Fig. S3). CCDC 2090920. For ESI and crystallographic data in CIF or other electronic format see DOI: 10.1039/d1cc04501f to bond to the larger chalcogenide and the smaller oxide anions, respectively. Such distinct layers can be defined as 2D building blocks. This has allowed the prediction of new functional compounds by stacking complementary layers of distinct chemical nature. ${ }^{14,15}$ The polar layered oxysulfide CaOFeS, a member of a family including non-linear optical materials, exhibits uncommon heteroleptic $\mathrm{FeS}_{3} \mathrm{O}$ tetrahedra and was investigated for magnetodielectric and photovoltaic effects. ${ }^{16,17}$ Other peculiar electronic and magnetic behaviors ${ }^{18-20}$ are found among oxychalcogenides. For instance, spin-glass behavior promoted by mixed anion interactions has been observed in the layered oxysulfides $\mathrm{Sr}_{4} \mathrm{Mn}_{2.91} \mathrm{O}_{7.40} \mathrm{Cu}_{2} \mathrm{~S}_{2}{ }^{21}$ and $\mathrm{Ba}_{2} \mathrm{Mn}_{2} \mathrm{O}_{4} \mathrm{Cu}_{0.9} \mathrm{~S}^{22}$ Magnetic frustration is a required ingredient for the observation of exotic quantum states. ${ }^{23-25}$ These are often studied in 3D oxides with corner sharing tetrahedral lattices such as spinels ${ }^{26}$ or pyrochlores. ${ }^{27}$ Apart from oxides, the fluoride $\mathrm{CsFe}_{2} \mathrm{~F}_{6}{ }^{28}$ pyrochlore and the In-diluted thiospinel $\mathrm{CdCr}_{2 x}$ $\mathrm{In}_{2(1-x)} \mathrm{S}_{4}{ }^{29,30}$ are spin-glass materials. In the $\mathrm{Bi}_{1.8} \mathrm{Fe}_{1.2} \mathrm{SbO}_{7}{ }^{31}$ pyrochlore, anion mixing through fluorination led to the variation of the spin glass dynamics.

We present an original oxysulfide with a noncentrosymmetric 3D-network involving corner-sharing tetrahedra. The structure is built with $0 \mathrm{D}$ Fe-based large magnetic clusters $\mathrm{Fe}_{13} \mathrm{O}_{12} \mathrm{~S}_{18}$ diluted with $\mathrm{Zn}$ and interconnected through silicate groups. The sulfur atoms provide intra-cluster bonding, while oxygen atoms are located on the outer shell of the clusters. The material orders into a spin-glass state at low temperature. Such 3D networks are scarce $^{32}$ for oxysulfides, which are dominated by low-dimensional structures. Furthermore, the elementary building blocks are large clusters instead of the common layered building blocks found in this class of materials. While the layered character brings interesting anisotropic electronic properties, a pressure-induced 2D-3D structural transition allowed drastic enhancement of electrical conductivity and photoelectric response in the $\mathrm{Bi}_{9} \mathrm{O}_{7.5} \mathrm{~S}_{6}$ oxysulfide. ${ }^{33}$ Here, the original Fe-based oxysulfide building block opens new perspectives for the design of functional phases combining oxide and chalcogenide anions in high dimensional structures. 
The new oxysulfide phase $\mathrm{Ba}_{10} \mathrm{Fe}_{7.75} \mathrm{Zn}_{5.25} \mathrm{~S}_{18} \mathrm{Si}_{3} \mathrm{O}_{12}$ was synthesized through a solid-state reaction in an evacuated sealed quartz tube (see ES1 $\dagger$ ). Its structure was solved and refined using single crystal X-ray diffraction (XRD) data (Tables S1-S3, ESI, $\dagger$ and CCDC deposition number 2090920). The treatment of the data was performed using Jana2006 ${ }^{34}$ and charge flipping $^{35}$ for structural solution and the least squares method for refinement. This phase crystallizes in a new structural type with the unit cell parameter $a=13.3380(1) \AA$ and the non-centrosymmetric space group $I \overline{4} 3 \mathrm{~m}$. Centrosymmetric trials led to unreasonable solutions. Thus, inversion twinning was allowed to refine, resulting in a Flack parameter of 0.04(8), indicating that the measured crystal was single-domain. Energy dispersive X-ray analysis on single crystals led to the average atomic ratio of 23.7/16.33/13.2/7.03/39.76 for $\mathrm{Ba} / \mathrm{Fe} / \mathrm{Zn} / \mathrm{Si} / \mathrm{S}$, respectively. This is in good agreement with the composition found at the end of the refinement, i.e. 22.7/17.6/11.9/6.8/40.9. In particular the $\mathrm{Zn} / \mathrm{Fe}$ distribution was determined to $0.56(3) /$ $0.44(3)$ at the Fe 2 site (see Table S2, ESI $\dagger$ ). The structure can be described as a 3D framework formed by repetitive 0D units, which are interconnected along the three crystallographic directions through $\mathrm{Si}^{4+}$ bridges. The $\mathrm{Si}^{4+}$ bridges form silicate groups having their oxygen atoms shared with the clusters.

These elementary cluster units (Fig. 1) are composed of one $\mathrm{Fe}_{1} \mathrm{~S}_{6}$ octahedron (Fig. 1b) decorated by twelve (Fe2/Zn1) $\mathrm{S}_{3} \mathrm{O}$ heteroleptic tetrahedra (Fig. 1c) arranged into four trimers. The later arrangement defines the $\left(\mathrm{Fe}_{1}(\mathrm{Fe} / \mathrm{Zn})_{12} \mathrm{O}_{12} \mathrm{~S}_{18}\right)$ magnetic clusters, see Fig. $1 \mathrm{~d}$ and e. In the $(\mathrm{Fe} / \mathrm{Zn}) \mathrm{S}_{3} \mathrm{O}$ tetrahedra, $\mathrm{Fe} 2(\mathrm{Zn} 1)$ is coordinated to two different types of anions with $d_{\mathrm{Fe} 2-\mathrm{S} 2}=2.311(2) \AA, d_{\mathrm{Fe} 2-\mathrm{S} 3}=2.332(2) \AA$ and $d_{\mathrm{Fe} 2-\mathrm{O} 1}=1.972(6) \AA$. The anionic segregation is such that the sulfur atoms provide intra-cluster bonding, while oxygen atoms are located at the outer shell of the clusters linked through $\mathrm{Si}^{4+}$ bridges. The observed environments follow Pearson's HSAB theory well. Then one can explain why a $3 \mathrm{D}$ structure is obtained in this particular case. Considering the coordination polyhedra stable in this structure $\mathrm{Fe}^{2+} \mathrm{S}_{6},(\mathrm{Fe} / \mathrm{Zn}) \mathrm{S}_{3} \mathrm{O}$ and $\mathrm{SiO}_{4}$, the cluster arrangement allows fulfilling the coordination preferences: $\mathrm{FeS}_{6}$ at the core shares sulphur with the surrounding $\mathrm{Fe} / \mathrm{ZnS}_{3} \mathrm{O}$ which point their unique apical oxygen outside the cluster to bond with the $\mathrm{Si}^{4+}$, the latter having the strongest affinity for oxygen.
Similar heteroleptic $\mathrm{FeOS}_{3}$ are present in the layered oxysulfide $\mathrm{CaFeSO}^{16}$ where they share corners to build layers separated by calcium sheets; similarly, $\mathrm{CaOZnS}^{36,37}$ contains tetrahedral $\mathrm{ZnOS}_{3}$. This $\mathrm{Fe}(\mathrm{Zn})$ environment remains uncommon. It is also found in the distinct structural type of $\mathrm{SrFe}_{2} \mathrm{~S}_{2} \mathrm{O}^{38}$ and $\mathrm{BaFe}_{2} \mathrm{~S}_{2} \mathrm{O}^{39}$ with more complex layers involving both tetrahedral corner and edge sharing. The $\mathrm{Fe} 1 \mathrm{~S}_{6}$ octahedra are connected to the tetrahedral $\mathrm{FeOS}_{3}$ and characterized by a longer bonding distance $\left(d_{\mathrm{Fe} 1-\mathrm{S} 2}=2.559(3) \AA\right)$ than in $\mathrm{FeOS}_{3}$ $\left(d_{\mathrm{Fe} 2-\mathrm{S} 2}=2.311(2) \AA, d_{\mathrm{Fe} 2-\mathrm{S} 3}=2.332(2) \AA\right)$ consistent with the calculated $\mathrm{Fe}^{2+}$ oxidation state. Regarding the mean oxidation state $\mathrm{Fe}^{+2.26}$ in the phase, it is consistent with the charge distribution deduced from the XPS and magnetic analysis shown later. The clusters are separated by $\mathrm{SiO}_{4}$ (Fig. 1f) groups by sharing all oxygen corners of $(\mathrm{Fe} / \mathrm{Zn}) \mathrm{S}_{3} \mathrm{O}$ with $d_{\text {Si1-O1 }}=1.628(5) \AA$. Each silicate group is connected to two different clusters. $\mathrm{Ba}^{2+}$ are located in the voids and their arrangement is shown and discussed in Fig. S1 (ESI $\dagger$ ).

A high purity powder could be obtained from the refined composition after many synthetic efforts. The Rietveld refinement based on the single crystal structure model converged with the unit cell parameter $a=13.3350$ (1) $\AA$ and the reliability factors $R_{\mathrm{obs}}=0.0323, \mathrm{w} R_{\mathrm{obs}}=0.0384, R_{\mathrm{all}}=0.0328, \mathrm{w} R_{\mathrm{all}}=0.0388$ and GOF $=3.29$. The results are consistent with the single crystal data (see Fig. S2 and Tables S6 and S7, ESI $\dagger$ ). A few low intensity peaks are found with the majority phase and could not be indexed with certainty with any existing phase. They do not indicate any straightforward symmetry change compared to the single crystal refinement either. Nevertheless, regarding the minor contribution of those peaks, we used our highest purity powder for the physical measurements considering the presence of a minor impurity for the interpretation.

In order to confirm the presence of both charges in $\left(\mathrm{Fe}^{2+/ 3+}\right)$ $\mathrm{S}_{3} \mathrm{O}$ tetrahedra and the general Fe charge distribution, the Fe $2 \mathrm{p}$ core level spectrum was examined. Reference data were taken on both vacuum fractured pyrrhotite $\left(\mathrm{Fe}_{7} \mathrm{~S}_{8}\right)$ and air-oxidized pyrrhotite as reported by Pratt et al. ${ }^{40}$ In this study, $\mathrm{Fe}_{7} \mathrm{~S}_{8}$ multiplet structure was generated based on theoretical $p$ core level multiplet structures for free transition metal ions calculated by Gupta and $\operatorname{Sen}^{41}$ and compared with the work of McIntyre and Zetaruk ${ }^{42}$ on $\mathrm{Fe}(\mathrm{II})$ and $\mathrm{Fe}(\mathrm{III})$ ions in iron oxides. The calculated integrated envelope (red line) is a reasonable fit
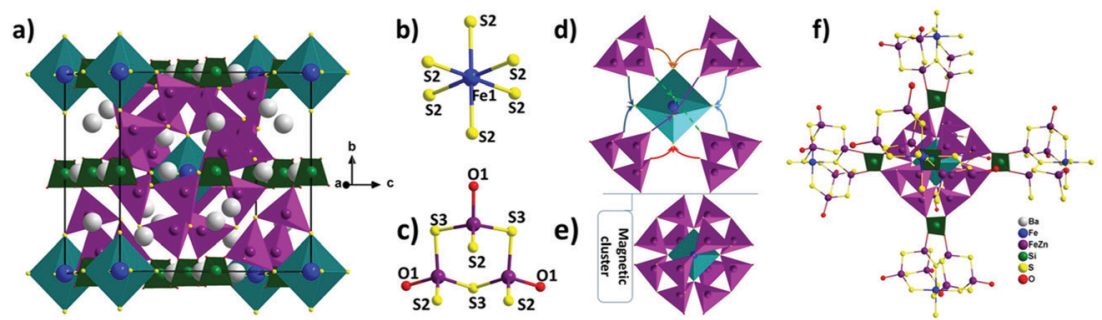

Fig. 1 (a) View of the unit cell of $\mathrm{Ba}_{10} \mathrm{Fe}_{7 \cdot 75} \mathrm{Zn}_{5 \cdot 25} \mathrm{~S}_{18} \mathrm{Si}_{3} \mathrm{O}_{12}$. (b) The octahedra $\mathrm{FeS}_{6}$. (c) Three heteroleptic tetrahedra FeS $\mathrm{O}_{3}$ connected by sharing $\mathrm{S}_{3}$, (d) connection of (b) and (c). (e) The magnetic cluster $\mathrm{Fe}_{1}(\mathrm{Fe} / \mathrm{Zn})_{12} \mathrm{O}_{12} \mathrm{~S}_{18}$ with $(\mathrm{Fe}, \mathrm{Zn}) \mathrm{S}_{3} \mathrm{O}$ tetrahedra in purple and $\mathrm{FeS}_{6}$ octahedra in blue. $\mathrm{SiO} \mathrm{O}_{4} \mathrm{groups}, \mathrm{Ba}$, $\mathrm{O}$ and $\mathrm{S}$ atoms are represented in green, grey, red and yellow, respectively. (f) Representation of how clusters connect each other through the ( $\mathrm{SiO}_{4}$ ) groups. Only the central cluster is fully represented to highlight the inter-clusters connection, Ba atoms are also omitted for clarity. 
to our experimental data (Fig. 2a), thus confirming the presence of mixed cation charges $\mathrm{Fe}^{3+} / \mathrm{Fe}^{2+}$. The major Fe(II) peak has a binding energy of $708.6 \mathrm{eV}$, which is similar to the fitted Fe(II)-S bonded peak binding energy of $\mathrm{Fe}_{7} \mathrm{~S}_{8}$ reported by Pratt et al., but slightly shifted to a higher binding energy. The binding energy of the main $\mathrm{Fe}$ (III) peak is $710.4 \mathrm{eV}$, which is similar to the fitted $\mathrm{Fe}(\mathrm{III})-\mathrm{O}$ binding energy of $\alpha-\mathrm{Fe}_{2} \mathrm{O}_{3}$ reported by McIntyre and Zetaruk which was $711.0 \mathrm{eV}$, although the $\mathrm{Fe}(\mathrm{III})$ peaks are slightly shifted to lower binding energies. The fact that Fe(III) peaks have been shifted to lower binding energies as compared to those observed for pure $\mathrm{Fe}(\mathrm{III})$ oxides, and that $\mathrm{Fe}(\mathrm{II})$ peaks have been shifted to higher binding energies as compared to those observed for pure $\mathrm{Fe}$ (II) sulfides reflects the mixed $\mathrm{Fe}-\mathrm{S} / \mathrm{Fe}-\mathrm{O}$ coordination in our system for both $\mathrm{Fe}$ (II) and $\mathrm{Fe}(\mathrm{III})$ species. Indeed, the percentage of the total signal derived from $\mathrm{Fe}(\mathrm{III})$ components in the spectrum is $36 \%$, whereas the expected distribution of iron in $\mathrm{Ba}_{10} \mathrm{Fe}_{7.75} \mathrm{Zn}_{5.25} \mathrm{Si}_{3} \mathrm{~S}_{18} \mathrm{O}_{12}$ corresponds to $25 \%$ of total iron with the $\mathrm{Fe}^{3+}$ oxidation state $\left(2^{*} \mathrm{Fe}^{3+}\right.$ and $5.75^{*} \mathrm{Fe}^{2+} ; 1^{*} \mathrm{Fe}^{2+}$ in the octahedral site). This suggests that some Fe(II) (S or O bonded) in the near-surface has been oxidized to Fe(III) and bonded to oxygen.

Fig. $2 \mathrm{~b}$ shows the temperature dependence of the resistivity for $\mathrm{Ba}_{10} \mathrm{Fe}_{7.75} \mathrm{Zn}_{5.25} \mathrm{Si}_{3} \mathrm{~S}_{18} \mathrm{O}_{12}$ which is typical of a semiconductor. The resistivity curve can be well fitted with the relation $\rho \propto \exp \left(\frac{\Delta g}{2 k_{\mathrm{B}} T}\right)$, where $\Delta g$ is the semiconductor band gap and $k_{\mathrm{B}}$ is the Boltzmann constant, leading to $\Delta g=0.4 \mathrm{eV}$. The zero field-cooled/field-cooled (ZFC/FC) magnetic measurements under a 1000 Oe field are shown in Fig. 3a and $\mathrm{b}$. The ZFC exhibits a maximum of $\sim 2.6 \mathrm{~K}$ and diverges from the FC data below this temperature. The inverse ZFC data were fit between 150 and $300 \mathrm{~K}$ with the Curie-Weiss law, $1 / \chi=T / C-\theta_{\mathrm{cw}} / C$, resulting in a large negative value $\theta_{\mathrm{cw}}=-343.9 \mathrm{~K}$, indicating strong antiferromagnetic (AFM) interactions between Fe ions, and $C=25.075 \mathrm{emu} \mathrm{K} \mathrm{mol}{ }^{-1}$. The effective moment $\mu_{\text {eff }}=5.09$ $\mu_{\mathrm{B}} / \mathrm{Fe}$ shows good agreement with the expected theoretical value for the refined distribution of high spin $(S=2) \mathrm{Fe}^{3+}$ and $(S=5 / 2) \mathrm{Fe}^{2+}$. Indeed, the calculation of the effective moment of 7.75 iron atoms per formula unit $\left(2 * \mathrm{Fe}^{3+}\right.$ and $\left.5.75 * \mathrm{Fe}^{2+}\right)$ leads to $5.16 \mu_{\mathrm{B}} / \mathrm{Fe}$, close to the experimental value of 5.09. The value $\left|\left(T_{\mathrm{cw}}\right) / T_{\mathrm{N}}\right| \approx 137.2$ indicates a strong frustration ${ }^{43}$ close, for instance, to the frustration parameter $\approx 135$ of $\mathrm{SrGa}_{12-x} \mathrm{Cr}_{x} \mathrm{O}_{19}{ }^{44}$ The evolution of $T_{\mathrm{f}}$ as a

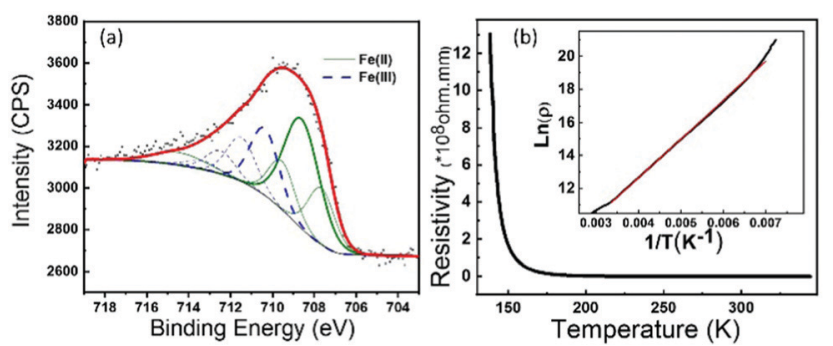

Fig. 2 (a) Fe $2 \mathrm{p}_{3 / 2}$ XPS spectrum of the $\mathrm{Ba}_{10} \mathrm{Fe}_{7 \cdot 75} \mathrm{Zn}_{5 \cdot 25} \mathrm{~S}_{18} \mathrm{Si}_{3} \mathrm{O}_{12}$ sample (square symbols). The green solid lines correspond to Fe(॥) (multiplets and satellite), the blue dotted lines correspond to Fe(ıI) (multiplet structure), and the red solid line represents the calculated integrated fit. (b) Temperature-dependent resistivity of $\mathrm{Ba}_{10} \mathrm{Fe}_{7.75} \mathrm{Zn}_{5 \cdot 25} \mathrm{~S}_{18} \mathrm{Si}_{3} \mathrm{O}_{12} ; \ln (\rho)$ versus $T^{-1}$ is fitted and shown in the inset. (a)

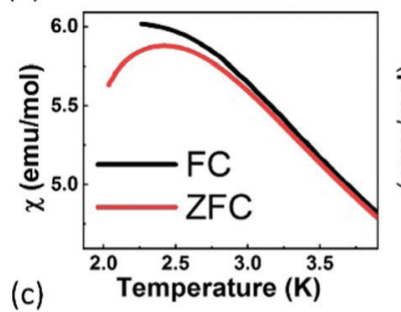

(b)

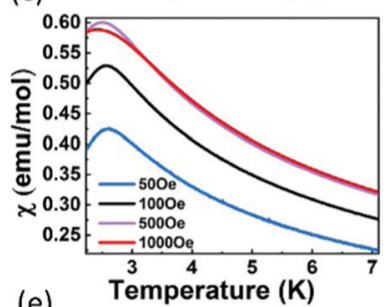

(e) Temperature (K)
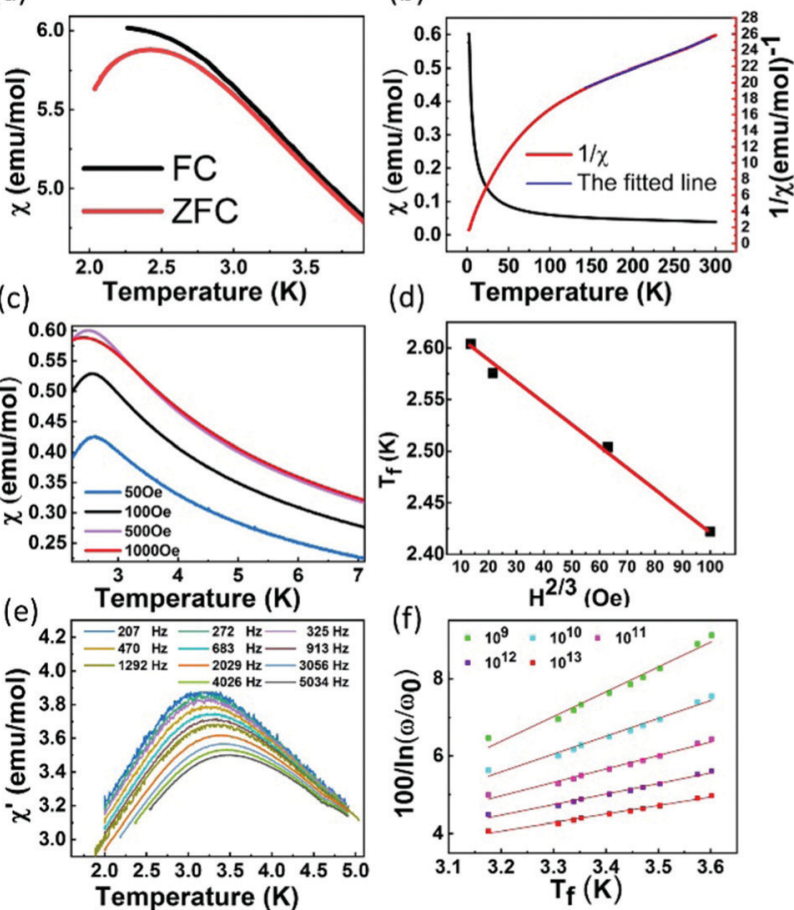

(d) Temperature (K)
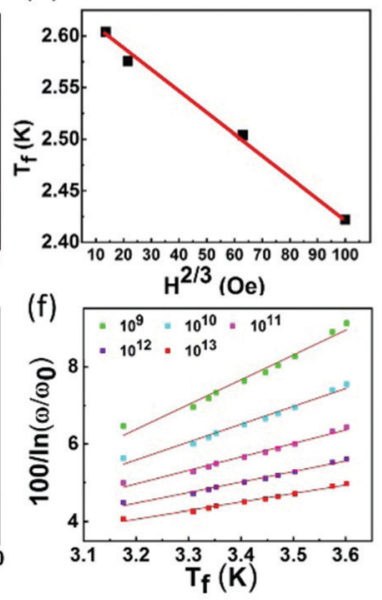

Fig. 3 (a) Zoom of ZFC/FC at low temperature. (b) ZFC/FC dc magnetic susceptibility with $1 / \chi$ fitted between 150 and $300 \mathrm{~K}$. (c) Evolution of $T_{\mathrm{f}}$ as a function of the applied magnetic field and (d) the Almeida-Thouless fit. (e) $\chi^{\prime}(T)$ measured at several fixed frequencies. (f) Vogel-Fulcher fit with different fixed $\omega_{0} / 2 \pi$ in the typical range of $10^{9}-10^{13} \mathrm{~Hz}$ for spin-glass.

function of the applied magnetic field (Fig. 3c) is well-fitted with the Almeida-Thouless relation ${ }^{45}$ (Fig. 3d) which is a good indicator of a spin-glass transition.

The AC magnetic susceptibility confirmed the spin-glass transition, as shown in Fig. 3e. The temperature dependence of the real part of the AC susceptibility at different frequencies with zero external DC magnetic field and an oscillating field of 16 Oe shows a typical temperature shift of a spin-glass. The AC susceptibility is frequency-dependent and has a nonzero imaginary component. It could be modeled by the Vogel-Fulcher law: ${ }^{46,47} \omega=\omega_{0} \exp \left[-E_{\mathrm{a}} / k_{\mathrm{B}}\right.$ $\left.\left(T_{\mathrm{f}}-T_{0}\right)\right]$, where $\omega_{0}$ is the characteristic frequency fixed to typical values for spin-glass following reported procedures, ${ }^{48} E_{\mathrm{a}}$ is the activation energy, $k_{\mathrm{B}}$ is the Boltzmann constant, $T_{\mathrm{f}}$ is the freezing temperature and $T_{0}$ is the Vogel-Fulcher temperature that gives a measure of the interaction effect. $T_{\mathrm{f}}$ should be proportional to $1 / \ln \left(\omega / \omega_{0}\right)$ for a spin glass. A linear variation is indeed obtained for each frequency. The fits to the data give $T_{0}$ from $1.36 \mathrm{~K}$ to $2.21 \mathrm{~K}$ (Fig. 3f and Table S8, ESI $\dagger$ ) in good agreement with the freezing temperature found by DC. For these values, $t^{*}=\left(T_{\mathrm{f}}-T_{0}\right) / T_{\mathrm{f}}$ is found in the range of $0.15-0.48$; $t^{*}$ above 0.15 is common for cluster spinglass materials. ${ }^{48,49}$

Comparatively, the layered $\mathrm{CaOFeS}$ and spin ladder $\mathrm{Ba}(\mathrm{Sr}) \mathrm{Fe}_{2} \mathrm{~S}_{2} \mathrm{O}$ phases described above show a partial long range AFM ordering and (canted)-AFM ordering, respectively. The behavior of $\mathrm{CaOFeS}$ is related to its frustrated triangular sheets and shows complex magnetodielectric effects. ${ }^{16,17,50}$ The latter 
phases are remarkable examples of 2D magnetic units based on $\mathrm{FeS}_{3} \mathrm{O}$ entities. The $\mathrm{Ba}_{5} \mathrm{Fe}_{6+x} \mathrm{~S}_{4+x} \mathrm{O}_{8}{ }^{51}$ phases represent another type of oxysulfide with spin-glass members and a complex structure with distorted $\mathrm{FeS}_{4} \mathrm{O}_{2}$ and $\mathrm{FeS}_{2} \mathrm{O}_{4}$ octahedral perovskite sub-units forming tunnels partially occupied by $\mathrm{Fe}$ and $\mathrm{S}$. In the title phase, we observe a new and remarkable arrangement of the $\mathrm{FeS}_{3} \mathrm{O}$ tetrahedra combined to decorate one $\mathrm{Fe}^{2+} \mathrm{S}_{6}$ octahedron to form large magnetic clusters. Note that, distinctly, magnetic clustering is known for ions without forming distinct entities such as in the Zn-diluted frustrated lattice $\mathrm{Zn}_{3} \mathrm{~V}_{3} \mathrm{O}_{8}{ }^{52}$ or in $\mathrm{Ba}_{9} \mathrm{~V}_{3} \mathrm{~S}_{15} .{ }^{53}$ Despite strong AFM interactions in our phase, frustration raises from competing intra-cluster interactions and $\mathrm{Zn}$ disturbing magnetic exchanges.

The properties discussed above are coherent with the complex magnetic exchange paths (Fig. S4 and Table S5, ESI $\dagger$ ) involving mixed valence. The magnetic paths J1-J6 are discussed in the ESI. $\dagger$ Intra-cluster magnetic interactions are mediated through sulfide anions, while weaker inter-cluster super-super-exchanges involve oxide anions.

The original cubic non-centrosymmetric oxysulfide $\mathrm{Ba}_{10} \mathrm{Fe}_{7.75} \mathrm{Zn}_{5.25} \mathrm{~S}_{18} \mathrm{Si}_{3} \mathrm{O}_{12}$ shows a $3 \mathrm{D}$-structure made of large diluted magnetic clusters, therefore standing apart from more commonly encountered layered oxychalcogenides. This partially charge-ordered phase presents strong AFM interactions with a spin-glass state arising from cluster geometry and disorder. It provides an exceptional new structure type and a rich playground for exotic physics.

\section{Conflicts of interest}

There are no conflicts to declare.

\section{Notes and references}

1 H. Kageyama, K. Hayashi, K. Maeda, J. P. Attfield, Z. Hiroi, J. M. Rondinelli and K. R. Poeppelmeier, Nat. Commun., 2018, 9, 772.

2 Y. Kamihara, T. Watanabe, M. Hirano and H. Hosono, J. Am. Chem. Soc., 2008, 130, 3296-3297.

3 J. W. Lynn and P. Dai, Phys. C, 2009, 469, 469-476.

4 B. Almoussawi, M. Huvé, V. Dupray, S. Clevers, V. Duffort, O. Mentré, P. Roussel, A. M. Arevalo-Lopez and H. Kabbour, Inorg. Chem., 2020, 59, 5907-5917.

5 T. Motohashi, M. Ito, Y. Masubuchi, M. Wakeshima and S. Kikkawa, Inorg. Chem., 2012, 51, 11184-11189.

6 (a) S. Gao, T. Broux, S. Fujii, C. Tassel, K. Yamamoto, Y. Xiao, I. Oikawa, H. Takamura, H. Ubukata, Y. Watanabe, K. Fujii, M. Yashima, A. Kuwabara, Y. Uchimoto and H. Kageyama, Nat. Commun., 2021, 12, 201; (b) J. M. Hodges, Y. Xia, C. D. Malliakas, T. J. Slade, C. Wolverton and M. G. Kanatzidis, Chem. Mater., 2020, 32, 10146-10154; (c) G. J. Limburn, M. J. P. Stephens, B. A. D. Williamson, A. Iborra-Torres, D. O. Scanlon and G. Hyett, J. Mater. Chem. A, 2020, 8, 19887-19897.

7 Y. F. Shi, W. B. Wei, X. T. Wu, H. Lin and Q. L. Zhu, Dalton Trans., 2021, 50, 4112-4118.

8 S. D. N. Luu and P. Vaqueiro, J. Materiomics, 2016, 2, 131-140.

9 J. Cui, C. Li and F. Zhang, ChemSusChem, 2019, 12, 1872-1888.

10 Q. Wang, M. Nakabayashi, T. Hisatomi, S. Sun, S. Akiyama, Z. Wang, Z. Pan, X. Xiao, T. Watanabe, T. Yamada, N. Shibata, T. Takata and K. Domen, Nat. Mater., 2019, 18, 827-832.

11 H. Kabbour, A. Sayede, S. Saitzek, G. Lefèvre, L. Cario, M. Trentesaux and P. Roussel, Chem. Commun., 2020, 56, 1645-1648.

12 K. Ueda, H. Hiramatsu, M. Hirano, T. Kamiya and H. Hosono, Thin Solid Films, 2006, 496, 8-15.
13 S. J. Clarke, P. Adamson, S. J. C. Herkelrath, O. J. Rutt, D. R. Parker, M. J. Pitcher and C. F. Smura, Inorg. Chem., 2008, 47, 8473-8486.

14 L. Cario, H. Kabbour and A. Meerschaut, Chem. Mater., 2005, 17, 234-236.

15 H. Kabbour, L. Cario, S. Jobic and B. Corraze, J. Mater. Chem., 2006, 16, 4165-4169.

16 C. Delacotte, O. Pérez, A. Pautrat, D. Berthebaud, S. Hébert, E. Suard, D. Pelloquin and A. Maignan, Inorg. Chem., 2015, 54, 6560-6565.

17 Y. Zhang, L. Lin, J.-J. Zhang, X. Huang, M. An and S. Dong, Phys. Rev. Mater., 2017, 1, 034406.

18 H. Kabbour, E. Janod, B. Corraze, M. Danot, C. Lee, M. H. Whangbo and L. Cario, J. Am. Chem. Soc., 2008, 130, 8261-8270.

19 J. B. He, D. M. Wang, H. L. Shi, H. X. Yang, J. Q. Li and G. F. Chen, Phys. Rev. B: Condens. Matter Mater. Phys., 2011, 84, 205-212.

20 S. Tippireddy, D. S. Prem Kumar, S. Das and R. C. Mallik, ACS Appl. Energy Mater., 2021, 4, 2022-2040.

21 G. Hyett, N. Barrier, S. J. Clarke and J. Hadermann, J. Am. Chem. Soc., 2007, 129, 11192-11201.

22 G. Hyett, Z. A. Gál, C. F. Smura and S. J. Clarke, Chem. Mater., 2008, 20, 559-566.

23 S. Kundu, T. Dey, A. V. Mahajan and N. Büttgen, J. Phys.: Condens. Matter, 2020, 32, 115601.

24 J. P. Sheckelton, J. R. Neilson, D. G. Soltan and T. M. McQueen, Nat. Mater., 2012, 11, 493-496.

25 C. A. Bridges, T. Hansen, A. S. Wills, G. M. Luke and J. E. Greedan, Phys. Rev. B: Condens. Matter Mater. Phys., 2006, 74, 1-9.

26 M. C. Kemei, P. T. Barton, S. L. Moffitt, M. W. Gaultois, J. A. Kurzman, R. Seshadri, M. R. Suchomel and Y. Il Kim, J. Phys.: Condens. Matter, 2013, 25, 326001.

27 A. F. Fuentes, K. Boulahya, M. Maczka, J. Hanuza and U. Amador, Solid State Sci., 2005, 7, 343-353.

28 S. Liu, Y. Xu, Y. Cui, J. Wang, K. Sun, S. Yu and X. Hao, J. Phys.: Condens. Matter, 2017, 29, 315501.

29 E. Vincent and V. Dupuis, Springer Ser. Mater. Sci., 2018, 275, 31-56. 30 E. Vincent, J. Hammann and M. Ocio, J. Stat. Phys., 2009, 135, 1105-1120.

31 A. V. Egorysheva, O. G. Ellert, O. M. Gaitko, M. N. Brekhovskikh, I. A. Zhidkova and Y. V. Maksimov, Inorg. Mater., 2017, 53, 962-968.

32 A. Meerschaut, A. Lafond, P. Palvadeau, C. Deudon and L. Cario, Mater. Res. Bull., 2002, 37, 1895-1905.

33 G. Zhang, Q. Zhang, Q. Hu, B. Wang and W. Yang, J. Mater. Chem. A, 2019, 7, 4019-4025.

34 V. Petříček, M. Dušek and L. Palatinus, Z. Kristallogr. - Cryst. Mater., 2014, 229, 345-352.

35 A. van der Lee, J. Appl. Crystallogr., 2013, 46, 1306-1315.

36 T. Sambrook, C. F. Smura, S. J. Clarke, K. M. Ok and P. S. Halasyamani, Inorg. Chem., 2007, 46, 2571-2574.

37 S. A. Petrova, V. P. Mar'evich, R. G. Zakharov, E. N. Selivanov, V. M. Chumarev and L. Y. Udoeva, Dokl. Chem., 2003, 393, 255-258.

38 H. Guo, M.-T. Fernández-Díaz, A. C. Komarek, S. Huh, P. Adler and M. Valldor, Eur. J. Inorg. Chem., 2017, 3829-3833.

39 M. Valldor, P. Adler, Y. Prots, U. Burkhardt and L. H. Tjeng, Eur. J. Inorg. Chem., 2014, 6150-6155.

40 A. R. Pratt, I. J. Muir and H. W. Nesbitt, Geochim. Cosmochim. Acta, 1994, 58, 827-841.

41 R. P. Gupta and S. K. Sen, Phys. Rev. B: Condens. Matter Mater. Phys., 1975, 12, 15-19.

42 N. S. McIntyre and D. G. Zetaruk, Anal. Chem., 1977, 49, 1521-1529.

43 S. Marik, D. Singh, B. Gonano, F. Veillon, D. Pelloquin and Y. Bréard, Scr. Mater., 2020, 186, 366-369.

44 B. Martínez, F. Sandiumenge, A. Rouco, A. Labarta, J. RodríguezCarvajal, M. Tovar, M. T. Causa, S. Galí and X. Obradors, Phys. Rev. B: Condens. Matter Mater. Phys., 1992, 46, 10786-10792.

45 D. Sherrington, J. Phys. A: Math. Gen., 1978, 11, L185-L188.

46 S. Shtrikman and E. P. Wohlfarth, Phys. Lett. A, 1981, 85, 467-470. 47 M. Ikeda and M. Aniya, J. Non-Cryst. Solids, 2013, 371-372, 53-57.

48 A. Kumar, R. P. Tandon and V. P. S. Awana, J. Magn. Magn. Mater., 2014, 349, 224-231.

49 J. A. Mydosh, Spin Glasses, CRC Press, 2014, p. 280.

50 S. F. Jin, Q. Huang, Z. P. Lin, Z. L. Li, X. Z. Wu, T. P. Ying, G. Wang and X. L. Chen, Phys. Rev. B: Condens. Matter Mater. Phys., 2015, 91, 094420.

51 T. Wright, Y. Prots and M. Valldor, Chem. - Eur. J., 2016, 8, 11303-11309.

52 T. Chakrabarty, A. V. Mahajan and S. Kundu, J. Phys.: Condens. Matter, 2014, 26, 405601.

53 B. Almoussawi, H. Tomohiri, H. Kageyama and H. Kabbour, Eur. J. Inorg. Chem., 2021, 1271-1277. 